\title{
ARTíCUlo
}

\section{Evaluación in vitro de bacterias marinas para potencial biocontrol en cultivo de moluscos bivalvos}

\author{
Evaluation in vitro of marine bacteria for potential biocontrol in culture of bivalve molluscs
}

\author{
Mery de la Fuente ${ }^{1,2^{* *}}$ y Víctor Faúndez ${ }^{3 * *}$ \\ ${ }^{1}$ Facultad de Medicina Veterinaria, Universidad San Sebastián, Lientur 1457, Concepción 4080871, Chile.*mdelafuentec@docente.uss.cl \\ ${ }^{2}$ Departamento de Ciencias Biológicas, Facultad de Ciencias de la Vida, Universidad Andres Bello, Autopista Concepción Talcahuano \\ \# 7100, Talcahuano, 4300866, Chile \\ ${ }^{3}$ Laboratorio de Genómica y Biotecnología Aplicada, Departamento de Medio Ambiente y Energía, Facultad de Ingeniería, Universidad \\ Católica de la Santísima Concepción, Alonso de Ribera 2850, Concepción, Chile.**vfaundez@ucsc.cl
}

\begin{abstract}
The cultivation of bivalve molluscs in controlled systems requires an adequate control of mortalities in larval stages due to bacterial infections. In this work, the activity of marine bacteria from coastal area of the Arauco Province, Chile to be used as a potential biocontroller in hatchery was investigated. Sampling of different matrices commonly associated with bivalve molluscs in their natural state was carried out and marine bacteria were isolated. The ability of these bacteria to inhibit three pathogenic bacteria normally associated with the culture of bivalve molluscs, Vibrio anguillarum, Vibrio splendidus and Vibrio parahaemolyticus was evaluated. In addition, a phenotypic characterization of the inhibitory strains was carried out, considering their properties of innocuousness and growth, for the practical use of these strains in culture systems. Of the 70 isolated bacteria, three strains were able to inhibit at least one bacterial pathogen and they were able to growth in seawater. The phenotypic characterization of these strains made it possible to identify them as belonging to the genus Vibrio and Pseudomonas. One strain was totally innocuous according to the characteristics evaluated in vitro. In conclusion the selection of bacteria with inhibitory and innocuous properties for a potential biocontrol in bivalve mollusc cultures is feasible in Arauco Province.
\end{abstract}

Key words: Biocontrol, molluscs, marine bacteria

Resumen.- El cultivo de moluscos bivalvos en sistemas controlados requiere un adecuado control de mortalidades en estados larvales debido a infecciones bacterianas. En este trabajo se investigó la actividad de bacterias marinas provenientes de zonas costeras de la provincia de Arauco, Chile para ser usadas como potencial biocontrolador en sistemas artificiales de cultivo. Se realizó el muestreo de diferentes matrices comúnmente asociadas a moluscos bivalvos en su estado natural y se procedió al aislamiento de bacterias marinas. Se evaluó la capacidad de estas bacterias para inhibir tres bacterias patógenas asociadas normalmente al cultivo de moluscos bivalvos, Vibrio anguillarum, Vibrio splendidus y Vibrio parahaemolyticus. Además, se realizó una caracterización fenotípica de las cepas con actividad inhibitoria, considerando sus propiedades de inocuidad y crecimiento, para la utilización práctica de estas cepas en sistemas de cultivo. De las 70 bacterias aisladas, tres cepas fueron capaces de inhibir al menos un patógeno bacteriano, logrando crecer en agua marina. La caracterización fenotípica de estas tres cepas permitió catalogarlas como pertenecientes a los géneros Vibrio y Pseudomonas. Una cepa marina fue totalmente inocua según las características evaluadas in vitro. Por tanto, es factible seleccionar bacterias con propiedades inhibitorias y de inocuidad para un potencial biocontrol en cultivos de moluscos bivalvos en la provincia de Arauco.

Palabras clave: Biocontrol, moluscos, bacterias marinas

\section{INTRODUCCIÓN}

El cultivo intensivo de bivalvos en sistemas de ambiente controlado o hatchery permite una fuente continua de semillas durante todo el año, para la acuicultura de muchas especies de recursos bentónicos de alto valor económico (Wurmann-Gotfrit 2008).

Se ha observado que las condiciones del cultivo larval de moluscos pueden favorecer el crecimiento de bacterias debido a la disponibilidad y acumulación de los metabolitos de las larvas y productos de excreción que sirvan de nutrientes para los microorganismos copiotróficos asociados a estos ambientes, siendo las larvas muy susceptibles a infecciones bacterianas (De la Fuente et al. 2015a). En efecto, se ha observado una tasa de crecimiento menor de semillas de Argopecten purpuratus (Lamarck, 1819), producidas en hatchery, en comparación a aquellas provenientes de ambiente natural (Pérez et al. 2012)

En estado embrionario o larvario de moluscos, por ejemplo, el proceso infeccioso es favorecido en muchas ocasiones por una mayor susceptibilidad debido a factores de estrés y condiciones tecnológicas inadecuadas incluyendo mala calidad del agua, contaminación orgánica 
y mortalidad natural, entre otras, facilitando estos factores el crecimiento de los agentes bacterianos patógenos como Vibrio anguillarum (Riquelme et al. 1995, Wurmann-Gotfrit 2008) y Vibrio splendidus (Rojas et al. 2015). Estos cuadros infecciosos producen mortalidades masivas que implica la pérdida de los stocks de producción y del suministro de semillas con serias consecuencias económicas para la sostenibilidad del proceso productivo (Romalde \& Barja 2010).

Las infecciones microbianas pueden afectar tanto a estados larvales como post-larvales y también a juveniles y adultos en su traspaso a los cultivos en el ambiente natural (Romalde \& Barja 2010). Estas infecciones pueden ser controladas por antibióticos, sin embargo, se corre el riesgo de seleccionar bacterias resistentes o de eliminar la microbiota benéfica en los sistemas de cultivo. Así también se debe considerar el problema bio-ecológico de desechar antibióticos a cursos de agua (Miranda et al. 2013). En el último tiempo, el mayor conocimiento sobre el rol de la microbiota asociada a estados larvales y la aplicación de bacterias benéficas a los cultivos permite vislumbrar el uso de estos organismos como una alternativa para el desarrollo de una nueva estrategia de control de patógenos en el cultivo de recursos hidrobiológicos. Algunos de los géneros con propiedades probióticas destacables corresponden a Vibrio, Pseudomonas y Bacillus (Prado et al. 2010, Sihag \& Sharma 2012, Karim et al. 2013, Atalah et al. 2015), así como también la aplicación de fagos (Onarinde \& Dixon 2018)

En esta investigación, se evaluaron las propiedades benéficas y de inocuidad de bacterias aisladas en caletas de la provincia de Arauco para su uso potencial como biocontrolador de patógenos en cultivos acuícolas. Para ello, se evaluó in vitro la capacidad de estas bacterias para inhibir patógenos bacterianos comúnmente asociados al cultivo de moluscos bivalvos. Estas cepas fueron seleccionadas y caracterizadas según sus propiedades fenotípicas, de inocuidad y crecimiento, para su utilización práctica en sistemas artificiales de cultivo como biocontrolador.

\section{MATERIALES Y MÉTODOS}

\section{RECOLECCIÓN DE MUESTRAS}

Se consideraron distintas matrices para el aislamiento de bacterias marinas: especímenes de moluscos bivalvos adultos, agua de mar, sedimento marino y algas marinas obtenidas desde Caleta Rumena (37 $10^{\prime} 26^{\prime \prime S}$; 7336'48”O), Caleta Piures $\left(37^{\circ} 13^{\prime} 55^{\prime \prime} \mathrm{S} ; 7^{\circ} 39^{\prime} 15^{\prime \prime} \mathrm{O}\right)$ y Caleta Llico (37¹1'37'S;73³3'51'O), correspondientes a zonas costeras de la provincia de Arauco, Biobío, Chile. Estas matrices tuvieron carácter no cuantitativo, es decir su único fin es la obtención de cepas bacterianas de trabajo. Para el muestreo de moluscos bivalvos se utilizaron 2 especímenes de Mytilus chilensis (Hupé, 1854) (un espécimen desde caleta Llico y un desde caleta Rumena), los cuales fueron depositados en una bolsa estéril (Interscience ${ }^{\circledR} 20 \times 30$ $\mathrm{cm})$. Para agua de mar se tomaron 3 muestras de agua de 500 mL, (1 desde caleta Llico, 1 desde caleta Rumena y 1 desde caleta Piures). Cada muestra se tomó en una botella de vidrio estéril (APHA 1999). Para sedimento se tomó una muestra de arena bentónica en caleta Rumena, la cual fue depositada en una bolsa estéril (Interscience ${ }^{\circledR}$ 20×30 $\mathrm{cm}$ ). Para el muestreo de algas se recogió un espécimen de Macrocystis pyrifera en caleta Llico, la cual fue depositada en una bolsa estéril (Interscience ${ }^{\circledR} 20 \times 30 \mathrm{~cm}$ ). Todas las muestras fueron trasladadas en frio al laboratorio de análisis de Biotecmar Servicios de la Universidad Católica de la Santísima Concepción para su posterior análisis.

\section{Aislamiento BaCteriano}

Las muestras fueron procesadas para el aislamiento bacteriano de la siguiente forma:

\section{AISLAMIENTO DESDE MUESTRAS DE CHORITOS ADULTOS}

Se realizó la disección respectiva de los especímenes, obteniéndose de forma aséptica todos los tejidos blandos incluyendo manto, branquias y masa visceral. Se realizó un homogenizado de estos tejidos en homogenizador de paleta Stomacher ${ }^{\circledR}$ por $3 \mathrm{~min}$. Se pesó $1 \mathrm{~g}$ de homogenizado que fue depositado en bolsas estériles (Interscience ${ }^{\circledR} 20 \times 30 \mathrm{~cm}$ ) con $9 \mathrm{~mL}$ de Solución Salina Marina (SSM), 24g L $\mathrm{L}^{-1} \mathrm{NaCl}$, $0,8 \mathrm{~g} \mathrm{~L}^{-1} \mathrm{KCl}, 7 \mathrm{~g} \mathrm{~L}^{-1} \mathrm{MgSO}_{4} \times 7 \mathrm{H}_{2} 0$, pH7 final. Se prepararon cinco diluciones seriadas al décimo $\left(10^{-1}, 10^{-2}, 10^{-3}, 10^{-4}\right.$, $10^{-5}$ ) en SSM a partir del primer homogenizado. Se sembró en duplicado $0,1 \mathrm{~mL}$ de cada dilución $\left(10^{-1}, 10^{-2}, 10^{-3}, 10^{-4}\right.$, $10^{-5}$ ) en placas de agar no selectivos y selectivos mediante la técnica de diseminación en superficie. Los medios no selectivos fueron Agar Tripticasa Soya (TSA)(Oxoid, Inglaterra) suplementado con $2 \%$ de $\mathrm{NaCl}$ y Agar Marino 2216 (Difco, BD, Franklin Lakes, NJ), y los medios de agar selectivo fueron agar Tiosulfato-Citrato Bilis-Sucrosa (TCBS)(Oxoid, Inglaterra) para el aislamiento de bacterias del género Vibrio, y agar Pseudomonas (Oxoid, Inglaterra) para el aislamiento de bacterias del género Pseudomonas, todas las placas se incubaron por $20 \mathrm{~h}$ a $22 \pm 2{ }^{\circ} \mathrm{C}$. Estos medios fueron utilizados para todos los aislamientos descritos más adelante.

\section{Aislamiento desde agua de Mar}

Para el aislamiento de bacterias provenientes de agua de mar, se realizaron 3 diluciones seriadas de cada muestra al décimo en $\operatorname{SSM}\left(10^{-1}, 10^{-2}, 10^{-3}\right)$ y se sembró $0,1 \mathrm{~mL}$ de la muestra original y de cada dilución $\left(10^{-1}, 10^{-2}, 10^{-3}\right)$ en duplicado sobre placas de agar selectivos y no selectivos (APHA 1999). 


\section{Aislamiento desde Sedimento}

Se pesó $1 \mathrm{~g}$ de la muestra de arena y fue resuspendida en $9 \mathrm{~mL}$ de SSM, luego homogenizada en un homogenizador Stomacher ${ }^{\circledR}$ por 3 min realizando 3 diluciones seriadas de la muestra al décimo en $\operatorname{SSM}\left(10^{-1}, 10^{-2}, 10^{-3}\right)$. Finalmente, se sembró $0,1 \mathrm{~mL}$ de la muestra original y de cada dilución $\left(10^{-1,} 10^{-2}, 10^{-3}\right)$ en duplicado sobre placas de agar selectivos y no selectivos.

\section{Aislamiento Desde algas}

Se realizó el aislamiento desde un macerado del alga obtenido mediante mortero. Se resuspendió $1 \mathrm{~g}$ de este macerado en $9 \mathrm{~mL}$ de $\mathrm{SSM}$ y se realizaron 2 diluciones seriadas de la muestra al décimo en $\operatorname{SSM}\left(10^{-1}, 10^{-2}\right)$, sembrando $0,1 \mathrm{~mL}$ de la muestra original y de cada dilución $\left(10^{-1}, 10^{-2}\right)$ en duplicado sobre agares selectivos y no selectivos. Se realizó, además, el aislamiento desde superficie de fijación deslizando una tórula sobre la superficie de zona de fijación del alga y luego se deslizó la tórula sobre la superficie de los agares, el aislamiento se realizó con asa de cultivo.

Para cada muestra, desde cada medio utilizado, se seleccionaron aquellas colonias que presentaron diferentes características morfológicas como tamaño, color, borde, elevación y superficie. Estas colonias fueron purificadas mediante traspaso a una nueva placa hasta obtención de un cultivo axénico. Las cepas fueron guardadas en cepario a $-20{ }^{\circ} \mathrm{C}$ en glicerol $20 \%$ en caldo soya triptona (TSB) (Oxoid, Inglaterra) con $1,5 \%$ de $\mathrm{NaCl}$, hasta realizar el posterior análisis de sus propiedades benéficas.

\section{Selección de baCterias SEgún PROPIEDadeS INHIBITORIAS DE VIBRIOS PATÓGENOS}

La prueba de inhibición se realizó mediante en ensayo doble capa descrito por Dopazo et al. (1988), enfrentando cada bacteria aislada a cada uno de los patógenos. Los patógenos utilizados fueron Vibrio anguillarum 3276 (De la Fuente et al. 2015b), Vibrio splendidus VPAP23 (Rojas et al. 2015) y Vibrio parahaemolyticus ATCC 17802. Para ello, en una placa de agar TSA se inoculó $10 \mu \mathrm{l}$ de un cultivo de $12 \mathrm{~h}$ de la bacteria de prueba (A625 entre 0,08 y 0,1) e incubó a $20{ }^{\circ} \mathrm{C}$ durante $24 \mathrm{~h}$. La colonia crecida fue muerta por exposición a vapores de cloroformo por $30 \mathrm{~min}$ y cubierta con la doble capa de TSB suplementado con $2 \%$ de $\mathrm{NaCl}$ y $0,9 \%$ de agar bacteriológico previamente inoculado con 100 $\mu 1$ de una dilución $10^{-1}$ de un cultivo de $12 \mathrm{~h}$ de la cepa testigo patógena (A625 entre 0,08 y 0,1). Después de un periodo de difusión de 15 a 30 min las placas fueron incubadas a 20 ${ }^{\circ} \mathrm{C}$ durante 2 a 4 días. La presencia de un halo de inhibición del crecimiento alrededor de la colonia se consideró como resultado positivo. El estudio se realizó en duplicado y el grado de inhibición se determinó midiendo el diámetro del halo, considerándose valores mayores a $5 \mathrm{~mm}$ como fuerte inhibición (Avendaño-Herrera et al. 2005). Las cepas positivas fueron preseleccionadas para estudios posteriores.

\section{CaRACTERIZACIÓN FenOtíPica de LAS CEPaS PRESELECCIONADAS}

Con el objetivo de aproximarse a la identidad de las cepas que resultaran positivas para inhibición en el ensayo anterior, se realizaron las siguientes pruebas según criterios conocidos para bacterias marinas: Tinción de Gram, Movilidad, Descarboxilación de la lisina, Licuefacción de la gelatina, Fermentación de glucosa, Presencia de catalasa, Presencia de oxidasa, Crecimiento en agar TCBS (Oliver 1982, Muroga et al. 1987, Montiel \& Lam 2001).

\section{ESTUDIO DE INOCUIDAD DE LAS CEPAS PRESELECCIONADAS}

Prueba de hemólisis: Se ensayó en una placa de agar sangre para determinar la hemólisis, sembrando las placas por el método de estría (Riquelme et al. 1997).

Susceptibilidad a los antibióticos de las cepas positivas: Se realiza el método estándar de difusión en agar sembrando en tapiz un inóculo bacteriano MacFarland 0,5 (Estándar de turbidez) en agar Müller-Hinton (Oxoid, Inglaterra), luego se depositó sobre este tapiz sensidiscos de antibióticos a ensayar según normas CLSI 2018. Se incubó la placa a 20 ${ }^{\circ} \mathrm{C}$ por $24 \mathrm{~h}$ y se midieron los diámetros de los halos de inhibición. Se determinaron los patrones de resistencia a los siguientes antibióticos (Oxoid, Inglaterra): amoxicilina $(2 \mu \mathrm{g})$, oxitetraciclina $(30 \mu \mathrm{g})$, eritromicina $(15 \mu \mathrm{g})$, florfenicol $(30 \mu \mathrm{g})$, flumequina $(30 \mu \mathrm{g})$ y ácido oxolínico (2 $\mu \mathrm{g})$ (CLSI 2018).

Detección de vibrios patógenos de humanos: La cepa inhibitoria que coincidió con las características del género Vibrio fue sometida a pruebas más específicas para descartar que se tratara de una de las 9 especies de vibrios patógenos de humanos con el fin de evitar un posible riesgo futuro de contaminación al inocular esta cepa en sistemas de cultivo artificial. Las pruebas utilizadas fueron realizadas según protocolo de Kaysner \& DePaola (2013).

\section{ESTUDIO DE INTERACCIÓN BACTERIANA DE CEPAS PRESELECCIONADAS}

Las cepas preseleccionadas que fueron positivas para inhibición se hicieron interactuar entre sí con el fin de evaluar si estas cepas podrían ser usadas en conjunto en un hatchery. El método utilizado fue el antagonismo en doble capa de Dopazo et al. (1988). 


\section{CARACTERIZACIÓN DEL CRECIMIENTO BACTERIANO DE CEPAS PRESELECCIONADAS}

Se realizó una curva de crecimiento de las cepas positivas para inhibición, en medio líquido (TSB $+2 \%$ de $\mathrm{NaCl}$ ) $\mathrm{y}$ en agua de mar esterilizada por filtración a en filtro de membrana 0,2 $\mu \mathrm{m}$ (Millipore), realizando conteos regulares hasta alcanzar la fase estacionaria para cada cepa. Las primeras $10 \mathrm{~h}$ de fase exponencial se realizó el recuento cada 2 o 3 h y luego se realizó el recuento a las 24,48 , o $72 \mathrm{~h}$ dependiendo de la cinética de cada cepa evaluada. La concentración bacteriana en el tiempo se detectó mediante la técnica de recuento bacteriano en placa, realizando 3 diluciones seriadas $\left(10^{-1}, 10^{-2}, 10^{-3}\right)$ de cada cultivo en SSM a la décima parte y sembrando $0,1 \mathrm{~mL}$ en TSA $+2 \%$ de $\mathrm{NaCl}$. Las curvas se realizaron a $20^{\circ} \mathrm{C}$. Se determinaron parámetros cinéticos en la fase exponencial de crecimiento realizando regresión lineal, a partir de lo cual se obtuvo la constante específica de crecimiento (k) correspondiente a la pendiente de la recta y se determinó el tiempo de generación (g) con la fórmula $\mathrm{g}=0,301 / \mathrm{k}$, donde $\mathrm{k}$ es la constante específica de crecimiento.

\section{Resultados}

\section{Aislamiento bacteriano}

A partir de las muestras marinas de zonas costeras de la provincia de Arauco se aislaron 70 cepas bacterianas de trabajo. Las cepas se aislaron mayoritariamente de muestras de agua de mar (32 cepas de 70) y los medios selectivos permitieron guiar el aislamiento principalmente a bacterias de los géneros Vibrio sp. (19 cepas de 70) y Pseudomonas sp. (22 cepas de 70) (Tabla 1).

\section{Selección de baCterias CON PROPIEdades INHIBITORIAS DE BACTERIAS PATÓGENAS}

De las 70 cepas estudiadas, 3 cepas resultaron inhibidoras de vibrios patógenos $(4,2 \%)$, por lo que fueron preseleccionadas para posteriores análisis (Tabla 2, Fig. 1). Sólo una bacteria tuvo la capacidad para inhibir el patógeno $V$. anguillarum, ésta correspondió a la cepa A5, aislada desde arena de caleta Rumena. El halo en 2 réplicas fue de $34 \mathrm{~mm}$, por lo que puede ser considerada como antagónica (Fig. 1). Dos cepas fueron capaces de inhibir $V$. parahaemolyticus, la cepa aislada desde muestras de chorito (cepa CCH18) y la cepa aislada desde alga (cepa CA6), el halo promedio en dos réplicas de estas cepas fue $20 \mathrm{~mm}$ y $15 \mathrm{~mm}$, respectivamente). Ninguna cepa logró inhibir $V$. splendidus.
Tabla 1. Aislamiento de cepas bacterianas desde muestras marinas de la provincia de Arauco / Isolation of bacterial strains from marine samples from provincia de Arauco

\begin{tabular}{|c|c|c|c|c|c|}
\hline \multirow{2}{*}{ Origen } & \multicolumn{4}{|c|}{$\mathrm{N}^{\circ}$ de cepas aisladas } & \multirow[b]{2}{*}{ Tota } \\
\hline & $\begin{array}{c}\text { Agar } \\
\text { marino }\end{array}$ & $\begin{array}{c}\text { Agar } \\
\text { TCBS }\end{array}$ & $\begin{array}{c}\text { Agar } \\
\text { Pseudomonas }\end{array}$ & $\begin{array}{l}\text { Agar } \\
\text { TSA2 }\end{array}$ & \\
\hline Adultos de Mytilus chilensis & 5 & 6 & 6 & 5 & 22 \\
\hline Agua de mar & 7 & 8 & 10 & 7 & 32 \\
\hline Superficie alga & 1 & 0 & 2 & 1 & 4 \\
\hline Macerado de alga & 1 & 2 & 1 & 1 & 5 \\
\hline Arena & 1 & 3 & 3 & 0 & 7 \\
\hline Total & 15 & 19 & 22 & 14 & 70 \\
\hline
\end{tabular}

Tabla 2. Actividad inhibitoria de cepas marinas sobre vibrios patógenos / Inhibitory activity of marine strains on pathogenic vibrios

\begin{tabular}{lccc}
\hline & \multicolumn{3}{c}{ Patógenos inhibidos (halo inhibitorio promedio en $\mathrm{mm})$} \\
\cline { 2 - 4 } & V. parahaemolyticus & V. anguillarum & V. splendidus \\
\hline A5 & - & $+(34,0 \mathrm{~mm})$ & - \\
CCH18 & $+(17,5 \mathrm{~mm})$ & - & - \\
CA6 & $+(12,0 \mathrm{~mm})$ & - & - \\
\hline
\end{tabular}

+: ocurre inhibición, -: no ocurre inhibición

\section{CARACTERIZACIÓN FENOTÍPICA DE BACTERIAS PRESELECCIONADAS}

Se analizaron las características bioquímicas de las cepas preseleccionadas, correspondientes a las bacterias marinas que resultaron positivas para inhibición de patógenos (Tabla 3). Las características detectadas coincidieron con las del género Vibrio para la cepa A5 y para el caso de las cepas $\mathrm{CCH} 18$ y CA6, coincidieron con las del género Pseudomonas, permitiendo identificar preliminarmente estas cepas.

\section{INOCUIDAD DE LAS CEPAS BACTERIANAS PRESELECCIONADAS}

Se realizaron pruebas de inocuidad de las 70 cepas aisladas inicialmente para seleccionar aquellas seguras y descartar potenciales patógenos. Del total de cepas aisladas, 15 presentaron hemólisis $(21,4 \%)$. En el caso de las cepas inhibitorias preseleccionadas, la cepa A5 presentó hemólisis $\beta$, lo que podría indicar un potencial patógeno, a diferencia de las cepas CCH18 y CA6, que no presentaron esta característica. 

a V. parahaemolyticus / Zones of inhibition of the pre-selected strains. A) Strain A5 inhibiting V. anguillarum B) Strains CCH18 and CA6 inhibiting $V$. parahaemolyticus
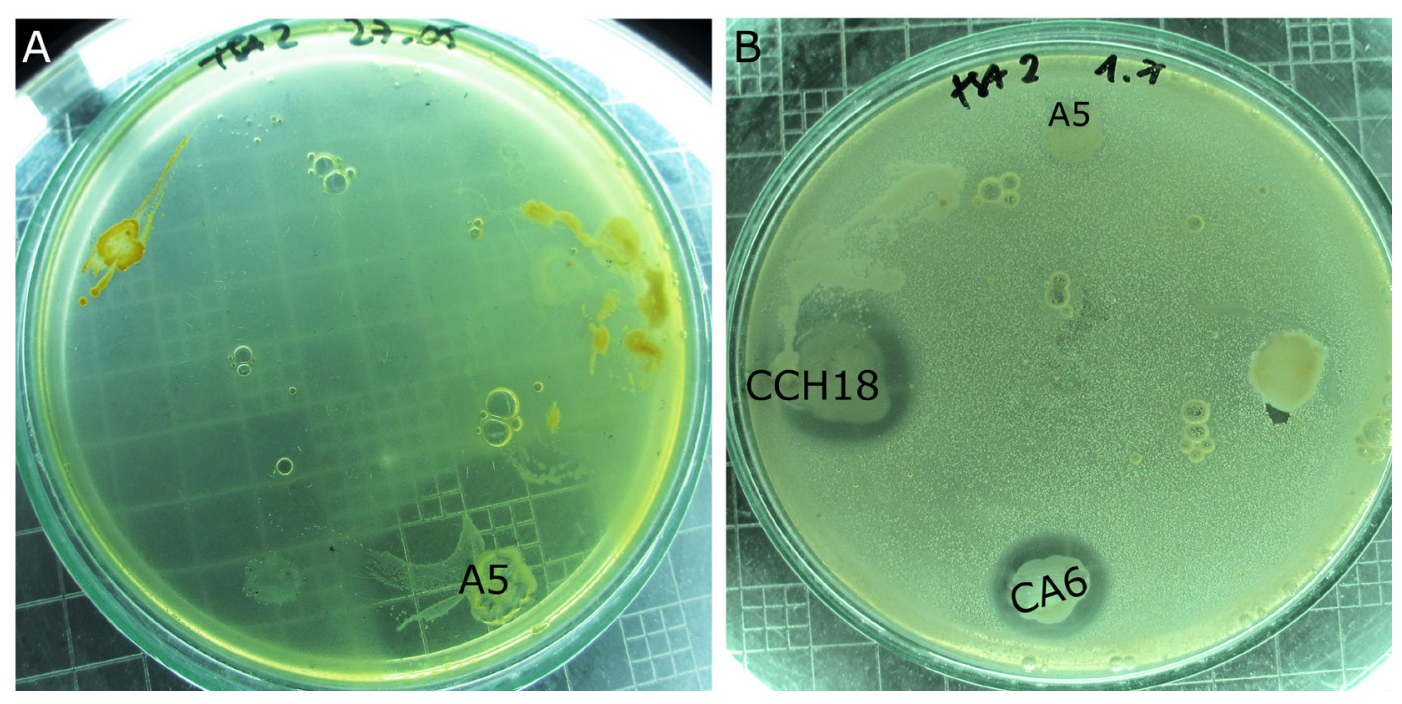

Tabla 3. Características fenotípicas de las cepas marinas preseleccionadas para biocontrol / Phenotypic characteristics of the marine strains preselected for biocontrol

\begin{tabular}{lccc}
\hline \multirow{2}{*}{ Característica } & \multicolumn{3}{c}{ Cepas preseleccionadas } \\
\cline { 2 - 4 } & A5 & CCH18 & CA6 \\
\hline Tinción Gram & bacilar (Gram -) & bacilar (Gram -) & bacilar (Gram -) \\
Oxidasa & + & + & + \\
Movilidad & +++ & + & + \\
Gelatinasa & + & - & - \\
Catalasa & + & + & + \\
Metabolismo glucosa & Fermentativo & NR & NR \\
Descarboxilación lisina & - & - & - \\
TCBS & verde & - & - \\
\hline Género bacteriano & Vibrio & Pseudomonas & Pseudomonas \\
\hline
\end{tabular}

+: reacción positiva, -: reacción negativa, NR: no reacciona

Con respecto al ensayo de susceptibilidad a antibióticos, las cepas preseleccionadas fueron susceptibles a casi la totalidad de los antibióticos. La cepa CA6 fue susceptible a todos los antibióticos ensayados, en cambio la cepa A5 presentó resistencia intermedia a eritromicina y $\mathrm{CCH} 18$ fue resistente a amoxicilina (Tabla 4).
Según el protocolo para la detección de vibrios patógenos BAM, la cepa A5 no correspondió a ninguna de las 9 especies de vibrios patógenos para humanos ( $V$. alginolyticus, $V$. cholerae, $V$. fluvialis, V. furnissii, $V$. hollisae, V. metschnikovii, V. mimicus, V. parahaemolyticus. V. vulnifucus), ni tampoco a las bacterias también patógenas: A. hydrophila y Plesiomonas shigelloides, quedando descartadas, según los resultados de las pruebas realizadas (Tabla 5). 
Tabla 4. Susceptibilidad de cepas preseleccionadas a diversos antibióticos / Susceptibility of preselected strains to various antibiotics

\begin{tabular}{lccc}
\hline \multirow{2}{*}{ Antibiótico } & \multicolumn{3}{c}{ Halo inhibitorio $(\mathrm{mm})[\mathrm{R}-\mathrm{I}-\mathrm{S}]^{*}$} \\
\cline { 2 - 4 } & A5 & CCH18 & CA6 \\
\hline Amoxicilina & $30[\mathrm{~S}]$ & $10[\mathrm{R}]$ & $25[\mathrm{~S}]$ \\
Oxitetraciclina & $32[\mathrm{~S}]$ & $27[\mathrm{~S}]$ & $25[\mathrm{~S}]$ \\
Eritromicina & $17[\mathrm{I}]$ & $30[\mathrm{~S}]$ & $28[\mathrm{~S}]$ \\
Florfenicol & $35[\mathrm{~S}]$ & $35[\mathrm{~S}]$ & $35[\mathrm{~S}]$ \\
Flumequina & $33[\mathrm{~S}]$ & $40[\mathrm{~S}]$ & $35[\mathrm{~S}]$ \\
Ac. oxolínico & $31[\mathrm{~S}]$ & $33[\mathrm{~S}]$ & $35[\mathrm{~S}]$ \\
\hline
\end{tabular}

*[R]: resistente, $[\mathrm{I}]$ :intermedio, $[\mathrm{S}]$ :susceptible

Tabla 5. Pruebas para identificación fenotípica de especies de vibrios patógenos aplicado a la cepa A5 / Tests for specific phenotypic identification of pathogenic vibrios for A5 strain

\begin{tabular}{|c|c|}
\hline Característica & Resultado \\
\hline AGS (Arginina-glucosa slant) & KK \\
\hline Ureasa & - \\
\hline \multicolumn{2}{|l|}{ Crecimiento en $(p / V)$ : } \\
\hline $\mathrm{O} \% \mathrm{NaCl}$ & - \\
\hline $1 \% \mathrm{NaCl}$ & + \\
\hline $3 \% \mathrm{NaCl}$ & + \\
\hline $6 \% \mathrm{NaCl}$ & + \\
\hline $10 \% \mathrm{NaCl}$ & + \\
\hline
\end{tabular}

KK: alcalino/alcalino, -: reacción o crecimiento negativo, + :reacción o crecimiento positivo

\section{INTERACCIÓN BACTERIANA ENTRE CEPAS PRESELECCIONADAS}

Las 3 cepas preseleccionadas se hicieron interactuar entre ellas, sólo la bacteria A5 logró inhibir las cepas CCH18 (halo de 13,8 mm) y CA6 (halo de $18 \mathrm{~mm}$ ), en cambio estas últimas no inhibieron a la cepa $\mathrm{A} 5 \mathrm{y}$ tampoco se inhibieron entre sí, indicando que las cepas CCH18 y CA6 pueden ser usadas en conjunto, pero que la cepa A5 debiera usarse sola.

\section{CRECIMIIENTO BACTERIANO DE CEPAS PRESELECCIONADAS}

Las 3 cepas evaluadas lograron crecer en caldo soya, A5 y CCH18 alcanzaron la fase estacionaria a las $24 \mathrm{~h}$, y una concentración de $1,6 \times 10^{11} \mathrm{UFC} \mathrm{mL}^{-1}$ y $4,0 \times 10^{9} \mathrm{UFC} \mathrm{mL}^{-1}$ respectivamente (Fig. 2). La cepa CA6 alcanzó la fase estacionaria a las $48 \mathrm{~h}$, y una concentración de $3,8 \times 10^{11}$ UFC $\mathrm{mL}^{-1}$. A partir de la fase exponencial se determinaron parámetros cinéticos, cuyos valores se indican en la Tabla 6.

En agua mar se obtuvo crecimiento de las cepas A5 y CCH18, alcanzando a las $8 \mathrm{~h}$ la fase estacionaria, con concentraciones de $1 \times 10^{8} \mathrm{UFC} \mathrm{mL}^{-1}$ y de $1 \times 10^{7} \mathrm{UFC} \mathrm{mL}^{-1}$, respectivamente. La cepa $\mathrm{CA} 6$ alcanzó la fase estacionaria con una concentración $1 \times 10^{7} \mathrm{UFC} \mathrm{mL}^{-1}$ a las $4 \mathrm{~h}$. Estas concentraciones fueron menores a las obtenidas en medio de cultivo, sin embargo, se alcanzó la fase estacionaria en un tiempo menor. Los parámetros cinéticos se indican en la Tabla 6. a)

b)
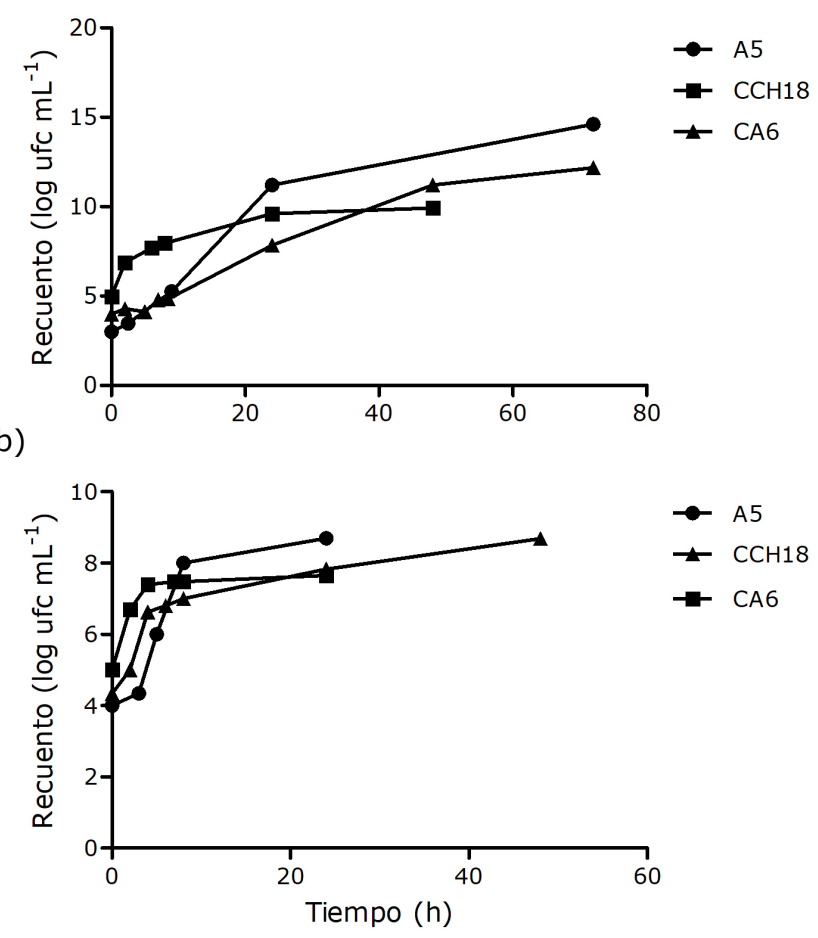

Figura 2. Curvas de crecimiento de las cepas preseleccionadas (A5, CA6, CCH18) en: a) caldo de cultivo soya triptona $+2 \%$ $\mathrm{NaCl} ; \mathrm{b})$ agua de mar / Growth curves of the preselected strains (A5, $\mathrm{CA} 6, \mathrm{CCH} 18$ ) in: a) tryptone soya broth $+2 \%$ $\mathrm{NaCl}$; b) seawater 
Tabla 6. Parámetros cinéticos en fase exponencial de cepas preseleccionadas en medio de cultivo y agua de mar / Kinetic parameters in exponential phase of preselected strains in culture medium and seawater

\begin{tabular}{|c|c|c|c|c|}
\hline \multirow[b]{2}{*}{ Cepa } & \multicolumn{2}{|c|}{ Crecimiento en medio de cultivo } & \multicolumn{2}{|c|}{ Crecimiento en agua de mar } \\
\hline & $\begin{array}{c}\text { Tiempo } \\
\text { generacional } \\
(\mathrm{g})\end{array}$ & $\begin{array}{l}\text { Constante de velocidad } \\
\text { específica de crecimiento } \\
(\mathrm{k})\end{array}$ & $\begin{array}{c}\text { Tiempo } \\
\text { generacional } \\
(\mathrm{g})\end{array}$ & $\begin{array}{c}\text { Constante de } \\
\text { velocidad específica } \\
\text { de crecimiento }(\mathrm{k})\end{array}$ \\
\hline A5 & $0,29 \mathrm{~h}$ & $1,04 \mathrm{~h}^{-1}$ & $0,16 \mathrm{~h}$ & $1,89 \mathrm{~h}^{-1}$ \\
\hline CA6 & $0,73 \mathrm{~h}$ & $0,41 \mathrm{~h}^{-1}$ & $0,16 \mathrm{~h}$ & $1,94 \mathrm{~h}^{-1}$ \\
\hline CCH18 & $0,22 \mathrm{~h}$ & $1,35 \mathrm{~h}^{-1}$ & $0,16 \mathrm{~h}$ & $1,86 \mathrm{~h}^{-1}$ \\
\hline
\end{tabular}

\section{DisCUSIÓN}

Las bacterias marinas son reconocidas por su versatilidad y potencial antimicrobiano, característica que puede ser aprovechada para su utilización en acuicultura en el control de patógenos (ElAhwany et al. 2015, Sayes et al. 2016, Salazar \& Sunagawa 2017). Existen varios trabajos que exploran esta posibilidad específicamente en la inhibición de patógenos asociados a moluscos bivalvos, principalmente del género Vibrio sp. (Riquelme et al. 1997, Long et al. 2005, Leyton \& Riquelme 2010, Leyton et al. 2014, Genard et al. 2014, De la Fuente et al. 2015b, León et al. 2016, Burks et al. 2017), en este tipo de trabajos se considera importante que las bacterias marinas sean aisladas desde el hábitat en el cual tendrán que cumplir su función, para asegurar así su habilidad de crecer en las condiciones de uso y su inocuidad (Verschuere et al. 2000). Con esa consideración, en este trabajo se aislaron bacterias marinas desde distintas matrices que tienen normalmente contacto con moluscos bivalvos en su ambiente natural en una zona costera de la provincia de Arauco, con el interés de aportar una herramienta para el desarrollo de acuicultura sostenible en esta zona. De las bacterias aisladas (70 cepas), un bajo porcentaje (3 cepas, 4,2\%) logró inhibir patógenos que pueden provocar infecciones en moluscos y/o humanos. Este resultado era esperado, ya que se ha reportado en general una baja incidencia de este tipo de cepas. Para la inhibición de $V$. parahaemolyticus, Pellón et al. (2001) describe un porcentaje similar de bacterias marinas inhibitorias cercano al 5\%, Leyton \& Riquelme (2010) describe un 17\% y Burks et al. (2017) describe un $7,8 \%$. Para la inhibición de $V$. anguillarum y $V$. splendidus los estudios son aún escasos y las bacterias inhibitorias son aisladas principalmente desde peces, por lo que no es comparable con lo descrito en este trabajo. Debido a los bajos porcentajes de cepas inhibitorias encontrados es siempre recomendable trabajar con un número de cepas adecuado que asegure la probabilidad de encontrar la característica inhibitoria deseada.
Esta investigación apuntó a determinar el potencial efecto inhibitorio de las especies aquí seleccionadas sobre el género Vibrio. Se ha descrito que los patógenos de este género son bacterias abundantes y normales en los sistemas marinos costeros. Éstas, en sistemas artificiales de cultivo, producen la muerte de los organismos hidrobiológicos, favorecido por el estrés de las especies cultivadas (Leyton \& Riquelme 2008). En particular, las especies $V$. anguillarum y $V$. splendidus, son patógenos reconocidos como causantes de vibriosis en cultivos de moluscos bivalvos y otras especies como peces y crustáceos, por ende, llegar a su control podría tener alto impacto en el área acuícola (Riquelme et al. 1995, Wurmann-Gotfrit 2008, Rojas et al. 2015). V. anguillarum, inhibido por la cepa seleccionada A5, es un patógeno que produce septicemia en las especies afectadas pudiendo incluso causar la muerte al cabo de 2 días (Hickey \& Lee 2018), de ahí que su control es de alta prioridad a nivel mundial. Por otra parte, $V$. parahaemolyticus, inhibido por las cepas preseleccionadas CA6 y CCH18, es un patógeno principalmente que afecta a humanos, causando infecciones asociadas a la ingestión de moluscos contaminados y los síntomas pueden ir desde una gastroenteritis hasta la septicemia, llegando a la muerte en pacientes inmunodeprimidos o con bajas defensas (Leyton \& Riquelme 2008). Como el cultivo de bivalvos tiene como objetivo final el consumo humano es importante también asegurar la inocuidad en este aspecto, evitando contaminar el agua con este tipo de bacterias patógenas.

Las 3 cepas que resultaron ser inhibidoras de estos patógenos fueron preseleccionadas (A5, CCH18 y CA6) y se procedió a realizar su caracterización fenotípica, coincidiendo con los géneros Vibrio (A5) y Pseudomonas (CCH18 y CA6), los cuales han sido descritos como géneros bacterianos con propiedades inhibitorias y de antagonismo con otras especies bacterianas (Riquelme et al. 1997, 2000, 2001; Kesarcodi-Watson et al. 2008). Cabe destacar que el género Vibrio, como se mencionó 
anteriormente, es comúnmente aislado desde agua marina y constituye un género de la microbiota normal de moluscos bivalvos, teniendo propiedades tanto probióticas como patógenas (Riquelme et al. 1994, Avendaño-Herrera et al. 2001, Godoy et al. 2011).

En la búsqueda de cepas no sólo inhibitorias, sino también inocuas, se analizó la capacidad hemolítica de ellas. Esta es una característica de algunas bacterias que constituye un factor de virulencia para humanos y animales debido a la presencia de hemolisinas, enzimas que lisan eritrocitos, por lo que esta característica es analizada en trabajos de evaluación de probióticos en acuicultura (Riquelme et al. 1997, FAO/WHO 2002, Escamilla-Montes et al. 2015, Abasolo-Pacheco et al. 2016). En este trabajo se encontró que un $21,4 \%$ de las cepas marinas producían hemólisis, porcentaje más bajo que el encontrado por Escamilla-Montes et al. (2015), quienes reportaron un porcentaje cercano al $50 \%$ en cepas de Bacillus y Lactobacillus aislados de moluscos y Sánchez-Ortiz et al. (2015) quienes encontraron cerca de $77 \%$ de hemólisis en cepas aisladas de moluscos. De las 3 cepas preseleccionadas en este trabajo, una fue hemolítica (cepa A5), lo que constituye un factor clave para descartar esta cepa como medida de prevención (Leyva-Madrigal et al. 2011, Escamilla-Montes et al. 2015). Considerando que la cepa A5 (Vibrio) resultó hemolítica, se evaluó fenotípicamente si ésta podría corresponder a una de las 9 especies de vibrios patógenas para humanos. Esta característica fue determinada mediante el protocolo establecido para la detección de estas especies patógenas, en este caso la cepa A5 no correspondió a ninguna de esas 9 especies de acuerdo a los resultados obtenidos.

Otra prueba de inocuidad importante fue evaluar la susceptibilidad a antibióticos de las cepas preseleccionadas. En este contexto, se encontró que las cepas analizadas fueron susceptibles a diversos antibióticos y la cepa CA6 fue susceptible a todos los antibióticos ensayados. Este resultado puede estar relacionado con el sector costero donde las cepas fueron recogidas, el que presenta una baja incidencia antrópica, con baja exposición a antibióticos y por ende baja presión selectiva sobre las bacterias allí existentes (Miranda et al. 2013). En general, la susceptibilidad a antibióticos encontrada en otros trabajos ha sido superior (Escamilla-Montes et al. 2015, SánchezOrtiz et al. 2015).

Aunque no fue determinada la identidad taxonómica a nivel de especie, las pruebas fenotípicas realizadas coincidieron con los géneros bacterianos Vibrio (cepa A5) y Pseudomonas (cepas CCH18 y CA6). Para conocer la especie en cuestión se podría realizar una identificación molecular mediante secuenciación de ADNr 16S tanto de la cepa de Vibrio como las cepas de Pseudomonas.
Se debe considerar que debido a la diversidad bacteriana marina (Salazar \& Sunagawa 2017) en ocasiones hay dificultades para resolver el nivel taxonómico de especie y algunos trabajos, aunque realizan identificación molecular, no consiguen determinar la especie analizada (Leyton \& Riquelme 2010, Sayes et al. 2016) y requieren aún más pruebas, como por ejemplo secuenciación de otros genes o espectrometría de masas, para su identificación (García et al. 2012).

Con el fin de acercarse a la aplicación práctica de estas bacterias en sistemas de cultivo se evaluó las interacciones entre las cepas preseleccionadas, se determinó que las cepas de Pseudomonas no son antagónicas entre ellas, por lo que podrían usarse en conjunto en hatchery potenciando el efecto benéfico de estas bacterias. Esta característica es importante ya que el uso de distintas bacterias permite acercarse a lo que ocurre en el ambiente natural, considerando que las bacterias no actúan en solitario sino formando parte de un complejo ecosistema.

Una característica importante cuando se aplican bacterias en sistemas de cultivo, es que las bacterias sean de fácil y rápido cultivo tanto en agua de mar como en medios de cultivo, lo que facilita su posterior manipulación (Jantzen et al. 2013, Escamilla-Montes et al. 2015, Sánchez-Ortiz et al. 2015). Al evaluar la capacidad de crecimiento de las 3 bacterias preseleccionadas se determinó que estas bacterias pueden crecer en agua de mar y en medio de cultivo, siendo la tasa de crecimiento más rápida en agua de mar que en un medio artificial. Considerando el agua de mar, como su ambiente natural, se puede esperar un crecimiento acelerado. No obstante, la fase estacionaria tuvo un nivel menor en este ambiente respecto de lo alcanzado en el medio de cultivo artificial, lo que se explicaría por un agotamiento más rápido de nutrientes en un cultivo de agua de mar. Maeda el al. (1997) reportó que en el mar la cantidad de bacterias puede alcanzar hasta $1 \times 10^{6} \mathrm{cel} \mathrm{mL}^{-1}$, así como también en el agua de mar tratada de un hatchery. En la presente investigación, un resultado destacable fue que en agua de mar las bacterias alcanzaran un crecimiento a las $8 \mathrm{~h}$ entre $10^{7}$ y $10^{8} \mathrm{UFC} \mathrm{mL}^{-1}$ (cepas CCH18 y A5, respectivamente) y las 4 h una concentración de $10^{7}$ para la cepa CA6, esto indica que, con las concentraciones obtenidas, las bacterias se pueden mantener en un estanque con agua marina para su aplicación como biocontrolador. Este resultado es muy interesante, considerando que se recomienda la inoculación cada 2 o 3 días, después de cada cambio de agua (Riquelme et al. 2001) y una dosis efectiva que según bibliografía debiera corresponder, como mínimo, a una concentración entre $5 \times 10^{3}$ cel mL $\mathrm{m}^{-1}$ y $1 \times 10^{6} \mathrm{cel} \mathrm{mL}^{-1}$ para lograr el efecto deseado (Riquelme et al. 2000, 2001; Aguilar-Macías et al. 2010). 
Finalmente, se concluye que fue posible seleccionar cepas con características benéficas in vitro, lo que demuestra que bacterias marinas aisladas desde la costa chilena de la provincia de Arauco tienen potencial uso como biocontrolador que ayude al desarrollo del cultivo en hatchery de moluscos bivalvos en esta zona. La cepa CA6, que inhibió a $V$. parahaemolyticus, fue la que reunió más características benéficas, a saber, no hemolítica, susceptible a todos los antibióticos y con rápido crecimiento en agua de mar. Una característica de la cepa CA6 es no ser antagónica respecto de la $\mathrm{CCH} 18$. Este hecho hace posible sugerir una evaluación in vivo de estas dos cepas en cultivos larvales de moluscos para determinar la sinergia que puedan desarrollar en la salud del cultivo de organismos hidrobiológicos. La importancia de este tipo de procedimiento de selección in vitro radica en la menor cantidad de cepas bacterianas que se requieran evaluar posteriormente sobre los cultivos larvales in vivo. Se recomienda evaluar las bacterias benéficas seleccionadas inoculándolas en los estanques de cultivos hidrobiológicos y determinar la supervivencia de larvas en presencia de estas bacterias. De ser exitosa la experiencia, las mejoras en las tasas de supervivencia permitirían aumentar sustancialmente la producción de semillas de moluscos bivalvos $\mathrm{u}$ otras especies de importancia comercial en la etapa de hatchery a nivel industrial.

\section{Agradecimientos}

Este estudio fue posible gracias al financiamiento del "Programa Piloto para el desarrollo de la Acuicultura en las Áreas de Manejo de la Provincia de Arauco e Isla Santa María”, ejecutado por la Universidad Católica de la Santísima Concepción (UCSC) y el Gobierno Regional del Biobío.

\section{LITERATURA CITADA}

Abasolo-Pacheco F, PE Saucedo, JM Mazón-Suástegui, D Tovar-Ramírez, R Araya, JM Ramírez-Orozco \& ÁI Campa-Córdova. 2016. Isolation and use of beneficial microbiota from the digestive tract of lions-paw scallop Nodipecten subnodosus and winged pearl oyster Pteria sterna in oyster aquaculture. Aquaculture 47(10): 30423051 .

Aguilar-Macías O, J Ojeda-Ramírez, A Campa-Córdova \& P Saucedo. 2010. Evaluation of natural and commercial probiotics for improving growth and survival of the Pearl Oyster, Pinctada mazatlanica, during late hatchery and early field culturing. Journal of the World Aquaculture Society 41(3): 447-454.

APHA. 1999. Standard methods for the examination of water and wastewater. Part 9000. Microbiological examination. American Public Health Association, American Water Works Association, Water Environment Federation, Washington. <https://www.mwa.co.th/download/file_ upload/SMWW_9000-10900a.pdf>
Avendaño-Herrera R, M Dekovic \& C Riquelme. 2001. Establishment of beneficial bacteria in the digestive tract and gonads for adult Argopecten purpuratus (Lamarck 1819) in mass culture. Revista de Biología Marina y Oceanografía 36: 31-41.

Avendaño-Herrera R, M Lody \& CE Riquelme. 2005. Producción de substancias inhibitorias entre bacterias de biopelículas en substratos marinos. Revista de Biología Marina y Oceanografía 40(2): 117-125.

Atalah J, G Hopkins, L Fletcher, A Castinel \& B Forrest. 2015. Concepts for biocontrol in marine environments: is there a way forward? Management of Biological Invasions $6(1): 1-12$.

Burks D, S Norris, KM Kauffman, A Joy, P Arevalo, RK Azad \& H Wildschutte. 2017. Environmental vibrios represent a source of antagonistic compounds that inhibit pathogenic Vibrio cholerae and Vibrio parahaemolyticus strains. Microbiology Open 6:504<https://doi.org/10.1002/ mbo3.504>

CLSI. 2018. Performance standards for antimicrobial disk and dilution susceptibility tests from bacteria isolated from animals, CLSI Document VET08. Clinical and Laboratory Standards Institute, Wayne

De la Fuente M, C Miranda \& V Faúndez. 2015a. Bacteriología asociada al cultivo de moluscos en Chile. Avances y perspectivas. Revista de Biología Marina y Oceanografía 50(1): 1-12.

De la Fuente M, C Miranda, P Jopia, G González-Rocha, N Guiliani, K Sossa \& H Urrutia. 2015b. Growth inhibition of bacterial fish pathogens and quorum-sensing blocking by bacteria recovered from Chilean salmonid farms. Journal of Aquatic Animal Health 27(2): 112-122. < doi: 10.1080/08997659.2014.1001534>

Dopazo C, M Lemos, C Lodeiros. J Bolinches, J Barja \& A Toranzo. 1988. Inhibitory activity of antibiotic-producing marine bacteria against fish pathogens. Journal of Applied Bacteriology 65: 97-101.

ElAhwany AM, HA Ghozlan, HA EISharif \& SA Sabry. 2015. Phylogenetic diversity and antimicrobial activity of marine bacteria associated with the soft coral Sarcophyton glaucum. Journal of Basic Microbiology 55(1): 2-10.

Escamilla-Montes R, A Luna-González, M Flores-Miranda, P Álvarez-Ruiz, J Fierro-Coronado, A Sánchez-Ortiz \& J Ávila-Leal. 2015. Isolation and characterization of potential probiotic bacteria suitable for mollusk larvae cultures. The Thai Journal of Veterinary Medicine 45(1): 11-2.

FAO/WHO. 2002. Guidelines for the evaluation of probiotics in food. Report of a Joint FAO/WHO Working Group report on Drafting Guidelines for the Evaluation of Probiotics in Food. London, Ontario, Canada, April 30 and May 1, 2002. <https://www.who.int/foodsafety/fs_management/ en/probiotic_guidelines.pdf $>$.

García P, F Allende, P Legarraga, M Huilcaman \& S Solari. 2012. Identificación bacteriana basada en el espectro de masas de proteínas: Una nueva mirada a la microbiología del siglo XX. Revista Chilena de Infectología 29(3): 263272. 
Genard B, O Larouche, JL Nicolas, P Miner, ML Beaudin \& R Tremblay. 2014. Effect of the probiotic strain Phaeobacter gallaeciensis after bacterial challenge on the complete larval development of Pecten maximus. Aquatic Living Resources 27(1): 27-34.

Godoy F, M Espinoza, G Wittwer, I Uriarte \& C Aranda. 2011. Caracterización de bacterias cultivables presentes en sistemas de cultivo de larvas de ostión chileno Argopecten purpuratus. Ciencias Marinas 37(3): 339-348.

Hickey M \& JL Lee. 2018. A comprehensive review of Vibrio (Listonella) anguillarum: ecology, pathology and prevention. Aquaculture 10(3): 585-610.

Karim M, W Zhao, D Rowley, D Nelson \& M GomezChiarri. 2013. Probiotic strains for shellfish aquaculture: Protection of Eastern Oyster, Crassostrea virginica, larvae and juveniles against bacterial challenge. Journal of Shellfish Research 32(2): 401-408.

Kaysner C \& A DePaola. 2013. Chapter 9. Vibrio. In: FDA's Bacteriological Analytical Manual (BAM). Food and Drug Administration, Silver Spring. $<$ https://www.fda.gov/food/ foodscienceresearch/laboratorymethods/ucm070830.htm>

Kesarcodi-Watson A, H Kaspar, M Lategan \& L Gibson. 2008. Probiotics in aquaculture: The need, principles and mechanisms of action and screening processes. Aquaculture 274: 1-14.

Leyva-Madrigal KY, A Luna-González, CM EscobedoBonilla, JA Fierro-Coronado \& IE MaldonadoMendoza. 2011. Screening for potential probiotic bacteria to reduce prevalence of WSSV and IHHNV in witheleg shrimp Litopenaeus vannamei under experimental conditions. Aquaculture 322-323: 16-22.

León J, JJ Aponte, D Cuadra, N Galindo, L Jaramillo, M Vallejo \& E Marguet. 2016. Actinomicetos aislados de Argopecten purpuratus productores de enzimas extracelulares y con actividad inhibitoria de patógenos marinos. Revista de Biología Marina y Oceanografía 51(1): 69-80

Leyton Y \& C Riquelme. 2008. Vibrios en los sistemas marinos costeros. Revista de Biología Marina y Oceanografía 43(3): 441-456.

Leyton Y \& C Riquelme. 2010. Marine Bacillus spp. associated with the egg capsule of Concholepas concholepas (Common name "Loco") have an inhibitory activity toward the pathogen Vibrio parahaemolyticus. Microbial Ecology 60: 599-605.

Leyton Y, K Pohl \& C Riquelme. 2014. Inhibición de la cepa patogénica de Vibrio cholerae (tor1) por Bacillus pumilus aislados del ambiente marino. Revista de Biología Marina y Oceanografía 49(3): 595-600.

Long R, D Rowley, E Zamora, J Liu, DH Bartlett \& F Azam. 2005. Antagonistic interactions among marine bacteria impede the proliferation of Vibrio cholera. Applied and Environmental Microbiology 71(12): 8531-8536.

Maeda M, K Nogami, M Kanematsu \& K Hirayama. 1997. The concept of biological control methods in aquaculture. Hydrobiologia 358: 285-290.

Miranda C, R Rojas, M Garrido, J Geisse \& G González. 2013. Role of shellfish hatchery as a reservoir of antimicrobial resistant bacteria. Marine Pollution Bulletin 74(1): 334-343.
Montiel F \& M Lam. 2001. Manual de microbiología clínica, 283 pp. Publicaciones Técnicas Mediterráneo, Santiago de Chile.

Muroga K, M Higashi \& H Keitoku. 1987. The isolation of intestinal microflora of farmed res seabream (Pagrus major) and Black Seabream (Acanthopagrus schlegeli) at larval and juvenile stages. Aquaculture 65: 79-88.

Oliver J. 1982. Taxonomic scheme for identification of marine bacteria. Deep Sea Research 29: 795-798.

Onarinde B \& R Dixon. 2018. Prospects for biocontrol of Vibrio parahaemolyticus contamination in blue mussels (Mytilus edulus)- a year-long study. Frontiers in Microbiology 5(9):1043. <doi: 10.3389/fmicb.2018.01043>

Pellón F, R Orozco \& J León. 2001. Bacterias marinas con capacidad antimicrobiana aislada de moluscos bivalvos en cultivos. Revista Peruana de Biología 8(2): 159-170.

Pérez E, C Azócar, AAraya, O Astudillo \& M Ramos. 2012. Comparación del crecimiento de Argopecten purpuratus entre cohortes obtenidas de captación de larvas en ambiente natural y de hatchery. Latin American Journal of Aquatic Research 40: 1026-1038.

Prado S, JL Romalde \& JL Barja. 2010. Review of probiotic for use in bivalve hatcheries. Veterinary Microbiology 145: 187-197.

Riquelme C, P Chávez, Y Morales \& G Hayashida. 1994. Evidence for parental bacterial transfer to larvae in Argopecten purpuratus (Lamarck, 1819). Biological Research 27: 129-134.

Riquelme C, G Hayashida, A Toranzo, J Vilches \& P Chávez. 1995. Pathogenicity studies on a Vibrio anguillarum related (VAR) strain causing an epizootic in Argopecten purpuratus larvae cultured in Chile. Diseases of Aquatic Organisms 22: 135-141.

Riquelme C, R Araya, N Vergara, A Rojas, M Guaita \& M Candia. 1997. Potential probiotic strains in the culture of the Chilean scallop Argopecten purpuratus (Lamarck, 1819). Aquaculture 154:17-26.

Riquelme C, R Araya \& R Escribano. 2000. Selective incorporation of bacteria Argopecten purpuratus larvae: implications for the use of probiotics in culturing systems of the Chilean scallop. Aquaculture 181: 25-36.

Riquelme C, M Jorquera, A Rojas, R Avendaño \& N Reyes. 2001. Addition of inhibitor-producing bacteria to mass cultures of Argopecten purpuratus larvae (Lamarck, 1819). Aquaculture 192: 111-119.

Rojas R, C Miranda, R Opazo \& J Romero. 2015. Characterization and pathogenicity of Vibrio splendidus strains associated with massive mortalities of commercial hatchery-reared larvae of scallop Argopecten purpuratus (Lamarck, 1819). Journal of Invertebrate Pathology 124: 61-69.

Romalde J \& J Barja. 2010. Bacteria in molluscs: good and bad guys. Current research, technology and education topics in applied microbiology and microbial biotechnology. Microbiology Books Series 1(2): 136-147.

Salazar G \& S Sunagawa. 2017. Marine microbial diversity. Current Biology 27(11): 489-494. 
Sánchez-Ortiz A, A Luna-González, Á Campa-Córdova1, R Escamilla-Montes, M Flores-Miranda \& J MazónSuástegui. 2015. Isolation and characterization of potential probiotic bacteria from pustulose ark (Anadara tuberculosa) suitable for shrimp farming. Latin American Journal of Aquatic Research 43(1): 123-136.

Sayes C, Y Leyton \& CE Riquelme. 2016. Bacteria Pseudoaltermonas sp. con potencial probiótico para cultivos larvales de peces. Latin American Journal of Aquatic Research 44(1): 76-84.

Sihag R \& P Sharma. 2012. Probiotics: The new ecofriendly alternative measures of disease control for sustainable aquaculture. Journal of Fisheries and Aquatic Sciences 7(2): 72-103.
Verschuere 1, G Rombaut, P Sorgeloos \& W Verstraete. 2000. Probiotic bacteria as biological control agents in aquaculture. Microbiology and Molecular Biology Reviews 64(4): 655-671.

Wurmann-Gotfrit C. 2008. Problemática y desafíos de la producción chilena de moluscos bivalvos en pequeña escala. En: Lovatelli A, A Farias \& I Uriarte (eds). Estado actual del cultivo y manejo de moluscos bivalvos y su proyección futura: factores que afectan su sustentabilidad en América Latina. Taller Técnico Regional de la FAO, Puerto Montt. Actas de Pesca y Acuicultura 12: 343-359.

Recibido 25 de mayo de 2019 y aceptado el 25 de septiembre de 2019

Editor: Claudia Bustos D. 